Клинико-функциональные нарушения сердечно-сосудистой системы у пациентов с хронической обструктивной болезнью легких при наличии хронической сердечной недостаточности

НИИ пульмонологии при Центральной научно-исследовательской лаборатории Алтайского государственного медицинского университета, г. Барнаул

\author{
Ya.N.Shoikhet, E.B.Klester
}

\title{
Clinical and functional cardiovascular disorders in patients with chronic obstructive pulmonary disease and chronic heart failure
}

\begin{abstract}
Summary
The study was aimed to investigate clinical and functional particularities of cardiovascular system in patients with COPD and chronic heart failure (CHF). We examined 1737 patients, of them, 498 with COPD (the 1st group), 721 with COPD and concomitant class I to III stable angina (the 2nd group), and 519 with class I to III stable angina (the 3rd group). All the patients also had CHF. The study included clinical assessment using modified R. Cody's scale, ECG, Holter monitoring, lung function testing, Doppler echocardiography, 6-minute walk test (6MWT). Obstructive disorders were found in 424 of the 2nd group patients (58.8\%) and 268 of the 3 rd group patients (51.7\%). Number of patients with class II to IV chronic cor pulmonale was similar in all groups. The class III was determined more often in the 2 nd group $(36.5 \% ; p<0.05)$, the class I prevailed in the 1 st group $(17.8 \% ; p<0.05)$. The stage I CHF predominated in the 1st group $(31.9 \% ; \mathrm{p}<0.05)$, the stages IIA and IIБ were seen mainly in the 2nd group $(51.6 \%$ and $26.4 \%$ respectively; $p<0.05$ ). The majority of the 3 rd group patients $(57.3 \%)$ had the stage IIA CHF. According to most clinical signs, CHF was more severe in the 2nd group. 6MWT was $308.08 \pm 6.03 \mathrm{~m}$ in the $1 \mathrm{st}$ group, $156.4 \pm 4.38 \mathrm{~m}$ in the 2nd group, and $212.8 \pm 5.65$ $\mathrm{m}$ in the 3 rd group $(p<0.05)$. Low left ventricular (LV) ejection fraction was seen significantly more often in COPD patients with concomitant angina. This group as well as COPD patients had significantly higher mean pulmonary artery pressure (mPAP) $(24.7 \pm 0.41 \mathrm{~mm} \mathrm{Hg}$ and $29.9 \pm 0.27 \mathrm{~mm}$ $\mathrm{Hg}$ respectively) compared to $21.7 \pm 0.07 \mathrm{~mm} \mathrm{Hg}$ in the 3rd group patients. Right ventricular (RV) diastolic dysfunction was revealed in 154 patients of the 1st group (83.7\%), 194 patients of the 2nd group (91.9\%) and 72 patients of the 3rd group (43.1\%). In conclusion, all the patients had RV and LV remodeling signs. COPD patients had more prominent RV hypertrophy and dilation, angina patients had enlargement of left heart and moderate decrease in LV contractility. The patients with COPD and angina had the greatest increase in size and wall thickness of both LV and RV and low pump function of LV.
\end{abstract}

\section{Резюме}

Целью исследования явилось изучение особенностей клинико-функциональных нарушений сердечно-сосудистой системы у больных ХОБЛ при наличии хронической сердечной недостаточности (ХСН). Обследовано 1737 пациентов: 498 - с ХОБЛ (1-я группа), $721-$ с сочетанием ХОБЛ и стенокардии напряжения I-III функциональных классов (ФК) (2-я группа), 519 - со стенокардией напряжения

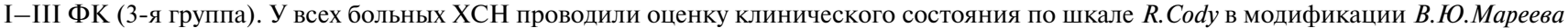
(ШОКС), ЭКГ, суточное мониторирование ЭКГ по Холтеру, функции внешнего дыхания, эходопплерокардиографию, тест с 6-минутной ходьбой (6-МШТ). Обструктивные нарушения легочной вентиляции разной степени выраженности имели 424 (58,8 \%) больных 2-й группы и 268 (51,7 \%) больных 3-й группы. Количество больных с хроническим легочным сердцем II и IV ФК было примерно одинаковым в группах. Больных с III ФК было больше во 2 -й группе $(36,5 \% ; p<0,05)$, І ФК - в 1-й группе $(17,8 \% ; p<0,05)$. ХСН I стадии чаще выявлялась в 1 -й группе $(31,9 \% ; p<0,05)$, ІІА и ІІБ стадий - во 2 -й группе $(51,6$ и $26,4 \%$ соответственно; $p<0,05)$. Более чем у $1 / 2$ пациентов 3-й группы $(57,3 \%)$ была диагностирована IIА стадия ХCH. По большинству клинических проявлений у больных 2-й группы ХСН была более тяжелой. Дистанция в 6-МШТ составила 308,08 \pm 6,03 м в 1-й группе, 156,4 \pm 4,38 м во 2-й группе и 212,8 \pm 5,65 м в 3й группе $(p<0,05)$. У больных с сочетанием ХОБЛ и ишемической болезни сердца (ИБС) низкая фракция выброса левого желудочка (ЛЖ) выявлялась достоверно чаще. В группах больных ХОБЛ и с сочетанием ХОБЛ и ИБС среднее давление в легочной артерии (СрДЛА) было значимо выше (24,7 $\pm 0,41$ и 29,9 \pm 0,27 мм рт. ст. соответственно) по сравнению с 21,7 $\pm 0,07$ мм рт. ст. в 3-й группе. Диастолическая дисфункция правого желудочка (ПЖ) выявлена у 154 (83,7 \%) больных 1-й группы, 194 (91,9 \%) больных 2-й группы и 72 $(43,1 \%)$ больных 3 -й группы. Таким образом, у больных всех групп наблюдались процессы ремоделирования ЛЖ и ПЖ. У пациентов с ХОБЛ были более выражены признаки гипертрофии и дилатации ПЖ, у больных ИБС - увеличение левых отделов сердца, а также некоторое снижение показателей сократимости ЛЖ, при сочетании ХОБЛ и ИБС наиболее выраженным было увеличение размеров и толщины стенок обоих желудочков и снижение насосной функции ЛЖ.

Сочетание хронической обструктивной болезни легких (ХОБЛ) и нарушений в системе кровообращения занимает лидирующее место среди заболеваний внутренних органов [1]. Это объясняется наличием общих факторов риска (табакокурение, влияние окружающей среды, алкоголизм, пожилой возраст) [2] и ведет к взаимному отягощению этих заболеваний в связи с общностью некоторых звеньев патогенеза.
Формирование вторичной легочной артериальной гипертензии увеличивает нагрузку на правые отделы сердца и левое предсердие, ухудшая тем самым состояние коронарного резерва и приводя к прогрессированию коронарной и легочно-сердечной недостаточности [3]. В то же время в ряде исследований показано, что у больных с хронической сердечной недостаточностью $(\mathrm{XCH})$ именно функция правого 
желудочка (ПЖ) связана с толерантностью к физической нагрузке, а фракция выброса (ФВ) ПЖ имеет самостоятельное значение для прогноза заболевания $[4,5]$. Существует мнение о наличии общего фактоpa, влияющего на изменения обоих желудочков. A. Kohama et al. [6] установили корреляцию между насыщением артериальной крови кислородом, ФВ левого желудочка (ЛЖ), нарушением функции ПЖ и процессом фиброза в каждом из них.

Целью исследования явилось изучение особенностей клинико-функциональных нарушений сердечно-сосудистой системы у больных ХОБЛ при наличии ХСН.

\section{Материалы и методы}

Обследованы 1737 пациентов. У 498 из них была ХОБЛ (1-я группа), у 721 - сочетание ХОБЛ с ишемической болезнью сердца (ИБС), стенокардией напряжения (СН) I-III функциональных классов (ФК) (2-я группа), у 518 больных - ИБС, СН I-III ФК (3-я группа). Все больные страдали ХСН. Наличие ХОБЛ с оценкой степени тяжести устанавливалось в соответствии с критериями GOLD (2003 г.). Выраженность сердечной недостаточности оценивалась по стадиям ХСН в соответствии с классификацией В.Х.Василенко и Н.Д.Стражеско (1935 г.), по функциональному классу в соответствии с Ньюйоркской классификацией (1964 г.). Критериями исключения являлись: наличие острых форм ИБС, декомпенсации кровообращения (III стадия ХCH), декомпенсация сахарного диабета.

Большинство обследуемых составляли мужчины: в 1-й группе - 82,5 \%, во 2-й - 84,9\%, в 3-й - 83,6\%. Средний возраст пациентов 1-й группы составил $62,10 \pm 0,57$ года, 2-й группы - 72,30 \pm 0,23 года $(p<0,05), 3$-й группы - 71,50 $\pm 0,28$ года. Средняя длительность течения ХОБЛ в 1-й группе была $17,5 \pm 0,4$ года, во 2-й группе - 21,70 $\pm 0,27$ года $(p<0,05)$. Средняя длительность течения ИБС во 2-й группе составила $16,6 \pm 0,21$ года, в 3-й - 18,1 0,24 года $(p<0,05)$. Индекс курения у пациентов 1-й группы равнялся 23,80 $\pm 0,72$, во 2-й группе $21,60 \pm 0,57$, в 3-й группе $-7,70 \pm 0,31(p<0,05)$.

Работа включала общепринятые клинико-рентгенологические исследования (в т. ч. оценку клинического состояния по шкале R.Cody в модификации B.Ю.Мареева - ШОКС) [7], методы функциональной диагностики (ЭКГ, в т. ч. суточное мониторирование ЭКГ по Холтеру, изучение функции внешнего дыхания (ФВД), эходопплерокардиографию) и соответствовала Национальным рекомендациям по диагностике и лечению ХСН 2006 г. [6]. Тест с 6-минутной ходьбой (6-МШТ) проводился в соответствии со стандартным протоколом [8]. Внутрисердечную и легочную гемодинамику исследовали посредством ультразвукового анализатора ViVid-7 ( GE, США) по стандартным методикам. Среднее давление в легочной артерии (СрДЛА) оценивали с помощью временных параметров систолического потока в легочной артерии. Определяли отношение времени ускорения потока (АТ) в выносящем тракте ПЖ к времени выброса (ЕT), затем по таблице вычисляли СрДЛА [9]. Стадии диастолической дисфункции (ДД) устанавливались согласно нормативам в зависимости от возраста [10] с учетом Национальных рекомендаций по диагностике и лечению ХСН [6].

Статистическую обработку полученных данных осуществляли с помощью методов вариационной статистики с использованием пакета программ Excel. Статистическую значимость различия средних определяли посредством критерия Стьюдента при уровне значимости $p<0,05$.

\section{Результаты и обсуждение}

У пациентов были обнаружены обструктивные нарушения различной степени выраженности, классифицированные по параметру объема форсированного выдоха за 1-ю с $\left(\mathrm{OФB}_{1}\right)$, и ИБС со стенокардией напряжения преимущественно II ФК: 424 (58,8 \%) и $268(51,7 \%)$ пациентов во 2-й и 3 -й группах соответственно.

ХОБЛ легкой и тяжелой степени чаще диагностировалась в 1-й группе - у 31,9 \% и 23,5 \% больных $(p<0,05)$ соответственно, ХОБЛ средней степени во 2-й группе $(42,9 \% ; p<0,05)$. Количество пациентов с крайне тяжелой степенью заболевания было одинаковым во всех группах. Степень выраженности дыхательной недостаточности определяли по клинической классификации, разработанной А.Г.Дембо (1957 г.), а впоследствии дополненной Н.Н.Канаевым $[11,12]$. Дыхательная недостаточность (ДН) I степени чаще отмечалась в 1-й группе - у 31,1 \% больных $(p<0,05)$, II степени - во 2-й группе $(51,2 \%$; $p<0,05)$. Доля пациентов с III степенью ДН была одинакова в сравниваемых группах. Количество больных с хроническим легочным сердцем II и IV ФК также было примерно одинаковым во всех группах. Пациентов с III ФК было больше во 2-й группе $(36,5 \% ; p<0,05)$, с I ФК - в 1-й группе $(17,8 \%$; $p<0,05)$

Средний ФК ХСН составил у пациентов 1-й группы 2,10 \pm 0,04, 2-й группы - 2,80 \pm 0,07, 3-й группы $-2,40 \pm 0,05(p<0,05)$. I стадия ХCH чаще выявлялась у пациентов 1-й группы (31,9\%; $p<0,05)$, II А и II Б - во 2-й группе $(51,6$ и $26,4 \%$ соответственно; $p<0,05)$. Более чем у $1 / 2$ пациентов 3 -й группы $(57,3 \%)$ была диагностирована IIA стадия ХCH. Во 2-й группе преобладали больные с постинфарктным кардиосклерозом (259 человек - 35,9\%) по сравнению с 3-й группой (163 человека - 31,5 \%). ХОБЛ в фазе обострения чаще наблюдалась при наличии сочетанной патологии (71,0\% во 2-й группе и $65,3 \%$ в 1-й группе; $p<0,05)$.

При анализе сопутствующей патологии выявлено преобладание больных с гипертонической болезнью, язвенной болезнью желудка во 2-й группе по сравнению с 1-й $(66,0$ и 17,9 \%; 57,8 и 14,1\% соответственно; $p<0,05)$. В группе пациентов с сочетанной патологией также чаще выявлялась патология почек: хронический цистит - у 331 (45,9\%) человек, 
хронический пиелонефрит - у 295 (40,9 \%) пациентов, хроническая почечная недостаточность - у 179 (24,8 \%) больных; в 1-й группе данными заболеваниями страдали соответственно 40,4; 34,9 и 19,3\% пациентов $(p<0,05)$. При изучении таких заболеваний как сахарный диабет, доброкачественная гиперплазия предстательной железы, не были выявлены различия по группам (у 19,1 и 26,5 \% пациентов 1-й группы и у 20,4 и 29,3 \% пациентов 2-й группы соответственно).

ШОКС позволила не только оценить выраженность каждого из симптомов, но и определить суммарную тяжесть состояния больного (табл. 1). На основании клинических проявлений у больных 2-й группы ХСН была более тяжелой, что выразилось в существенной разнице в баллах по ШОКС.

Дистанция 6-МШТ колебалась от 308,08 \pm 6,03 м в 1-й группе до 156,40 \pm 4,38 м во 2-й группе и 212,80 $\pm 5,65$ м - в 3-й $(\mathrm{p}<0,05)$. Сопоставление полученных результатов с нормативами 6-МШТ, предложен- ными в Национальных рекомендациях по диагностике и лечению ХСН (2006 г.), позволило выявить III ФК ХСН у пациентов с сочетанной патологией, а также с ИБС, в то время как у пациентов с ХОБЛ II ФК ХCH, что у больных 3-й группы не соответствовало баллам по ШОКС. Известно, что исследование тяжести ХСН у пациентов старше 75 лет с помощью 6-МШТ может приводить к завышению ФК $\mathrm{XCH}$ из-за выраженного влияния сопутствующей патологии [8].

Нарушения липидного обмена выражались в гиперхолестеринемии, гипертриглицеридемии, высокой концентрации холестерин-липопротеидов низкой плотности (ХC ЛПНП), пониженном содержании холестерин-липопротеидов высокой плотности (ХС ЛПВП). Все эти проявления у больных всех групп существенно превышали целевые уровни (табл. 2), указанные в "Российских рекомендациях по диагностике и коррекции нарушений липидного обмена" [13].

Таблица 1

Клиническое состояние больных с ХСН по ШОКС

\begin{tabular}{|c|c|c|c|c|c|c|c|c|c|c|}
\hline \multirow{3}{*}{ Показатели } & & \multicolumn{3}{|c|}{ 1-я группа (ХОБЛ), n= 498} & \multicolumn{3}{|c|}{ 2-я группа (ХОБЛ и ИБС), n= 721} & \multicolumn{3}{|c|}{ 3-я группа (ИБС), $n=518$} \\
\hline & & \multirow[t]{2}{*}{ абс.число } & \multicolumn{2}{|c|}{$\%$} & \multirow[t]{2}{*}{ абс. число } & \multicolumn{2}{|c|}{$\%$} & \multirow[t]{2}{*}{ абс.число } & \multicolumn{2}{|c|}{$\%$} \\
\hline & & & $p$ & $\pm m$ & & $p$ & $\pm m$ & & $p$ & $\pm m$ \\
\hline \multirow[t]{3}{*}{ Одышка } & нет & 35 & 7,0 & 1,15 & 36 & 5,0 & 0,81 & 31 & 6,0 & 1,04 \\
\hline & в покое & 358 & 71,9 & 2,01 & 476 & $66,0^{*}$ & 1,76 & 410 & $79,1^{* *}$ & 1,79 \\
\hline & при нагрузке & 105 & 21,1 & 1,83 & 209 & $29,0^{*}$ & 1,69 & 77 & 14,9 ** & 1,56 \\
\hline $\begin{array}{l}\text { Увеличение массы } \\
\text { тела за последнюю } \\
\text { неделю }\end{array}$ & & 70 & 14,1 & 1,56 & 137 & $19,0^{*}$ & 1,46 & 72 & 13,9 ** & 1,52 \\
\hline $\begin{array}{l}\text { Жалобы на перебои } \\
\text { в работе сердца }\end{array}$ & & 178 & 35,7 & 2,15 & 455 & $63,1^{*}$ & 1,80 & 278 & $53,7^{* *}$ & 2,19 \\
\hline Положение & горизонтально & 186 & 37,4 & 2,17 & 151 & $20,9^{*}$ & 1,52 & 157 & $30,3^{* *}$ & 2,02 \\
\hline \multirow[t]{3}{*}{ в постели } & $\begin{array}{l}\text { с приподнятым } \\
\text { изголовьем }\end{array}$ & 185 & 37,2 & 2,17 & 313 & $43,4^{*}$ & 1,85 & 255 & $49,3^{* *}$ & 2,20 \\
\hline & $\begin{array}{l}\text { просыпаются } \\
\text { ночью }\end{array}$ & 101 & 20,2 & 1,80 & 186 & $25,8^{*}$ & 1,63 & 83 & $16,0^{* *}$ & 1,61 \\
\hline & сидя & 26 & 5,2 & 0,99 & 71 & $9,9^{*}$ & 1,11 & 23 & $4,4^{* *}$ & 0,91 \\
\hline Набухшие шейные & нет & 310 & 62,3 & 2,17 & 377 & $52,3^{*}$ & 1,86 & 350 & $67,6^{* *}$ & 2,06 \\
\hline \multirow[t]{2}{*}{ вены } & лежа & 147 & 29,5 & 2,04 & 255 & $35,4^{*}$ & 1,78 & 132 & $25,4^{* *}$ & 1,91 \\
\hline & стоя & 41 & 8,2 & 1,23 & 89 & $12,3^{*}$ & 1,22 & 36 & $7,0^{* *}$ & 1,12 \\
\hline Влажные хрипы & нет & 191 & 38,4 & 2,18 & 178 & $24,7^{*}$ & 1,61 & 219 & $42,3^{* *}$ & 2,17 \\
\hline \multirow[t]{3}{*}{ в легких } & нижние отделы & 241 & 48,4 & 2,24 & 373 & 51,7 & 1,86 & 223 & $43,1^{\star *}$ & 2,18 \\
\hline & до лопаток & 45 & 9,0 & 1,29 & 104 & $14,4^{*}$ & 1,31 & 55 & $10,6^{\star *}$ & 1,35 \\
\hline & $\begin{array}{l}\text { над всей } \\
\text { поверхностью }\end{array}$ & 21 & 4,2 & 0,90 & 66 & $9,2^{\star}$ & 1,07 & 21 & $4,0^{* *}$ & 0,87 \\
\hline Наличие ритма галопа & & 101 & 20,3 & 1,80 & 187 & $25,9^{*}$ & 1,63 & 81 & $15,6^{* *}$ & 1,60 \\
\hline \multirow[t]{3}{*}{ Увеличение печени } & нет & 284 & 57,1 & 2,22 & 312 & $43,3^{*}$ & 1,85 & 294 & $56,8^{* *}$ & 2,18 \\
\hline & $<5 \mathrm{~cm}$ & 178 & 35,7 & 2,15 & 315 & $43,7^{*}$ & 1,85 & 182 & $35,1^{* *}$ & 2,10 \\
\hline & $>5 \mathrm{~cm}$ & 36 & 7,2 & 1,16 & 94 & $13,0^{*}$ & 1,25 & 42 & $8,1^{* *}$ & 1,20 \\
\hline \multirow[t]{3}{*}{ Отечный синдром } & нет & 253 & 50,8 & 2,24 & 287 & $39,8^{*}$ & 1,82 & 241 & $46,5^{\star *}$ & 2,19 \\
\hline & пастозность & 124 & 24,9 & 1,94 & 221 & $30,7^{*}$ & 1,72 & 153 & 29,6 & 2,00 \\
\hline & отеки & 121 & 24,3 & 1,92 & 213 & $29,5^{*}$ & 1,70 & 124 & $23,9^{* *}$ & 1,87 \\
\hline Уровень систоличес- & $>120$ & 307 & 61,7 & 2,18 & 542 & $75,2^{*}$ & 1,61 & 353 & $68,2^{* *}$ & 2,05 \\
\hline кого артериального & $100-120$ & 165 & 33,1 & 2,11 & 111 & $15,4^{*}$ & 1,34 & 132 & $25,4^{\star *}$ & 1,91 \\
\hline давления, мм рт. ст. & $<100$ & 26 & 5,2 & 0,99 & 68 & $9,4^{*}$ & 1,09 & 33 & $6,4^{* *}$ & 1,07 \\
\hline шОКС, сумма баллов & & & $4,1=$ & & & $7,3 \pm$ & & & $5,4 \pm C$ & \\
\hline
\end{tabular}

Примечания: * - статистически значимые различия $(p<0,05)$ между 1-й и 2-й группами; ** - статистически значимые различия $(p<0,05)$ между 2-й и 3-й группами. 
Показатели липидного обмена

\begin{tabular}{l}
\multicolumn{1}{c}{ Показатели } \\
Общий холестерин (< 5,0 ммоль/л) \\
ХС лПнП (<3,0 ммоль/л) \\
ХС лПВП (> 1,2 ммоль/л) \\
Триглицериды (< 1,77 ммоль/л)
\end{tabular}

Триглицериды (< 1,77 ммоль/л)

1 -я группа (ХОБл), $n=498$
$5,17 \pm 0,04$
$3,68 \pm 0,02$
$0,95 \pm 0,01$
$1,98 \pm 0,01$

1 -я группа (ХОБЛ), $n=498$

$3,68 \pm 0,02$

$1,98 \pm 0,01$

2-я группа (ХОБЛ и ИБС), $n=721$
$7,68 \pm 0,03^{*}$
$5,61 \pm 0,02^{*}$
$0,87 \pm 0,01^{*}$
$2,01 \pm 0,01^{*}$

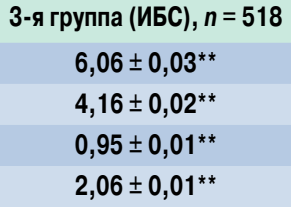

Указанные изменения липидного обмена соответствуют IIb типу дислипидемий по классификации A.Fredrikson. Выявленный атерогенный тип гиперлипидемии свидетельствует о том, что ХОБЛ, вероятно, способствует развитию атеросклероза.

Основные эхокардиографические показатели представлены в табл. 3. У пациентов 1-й группы ФВ ЛЖ составила $58,8 \pm 0,37 \%$, а сердечный индекс $3,0 \pm 0,07$ л/мин/м ${ }^{2}$, что было расценено как состояние относительно сохранной сократительной способности миокарда и инотропной функции сердца. У больных с сочетанной патологией размеры правых и левых отделов сердца оказались больше, чем в 1-й и 3-й группах, а ФВ была ниже. Наблюдалось значимое увеличение размеров левого предсердия у больных 2-й и 3-й групп, что косвенно свидетельствует о повышении давления наполнения и снижении функции ЛЖ. В этих же группах отмечалось увеличение конечно-диастолического размера (КДР) и конечно-систолического размера (КСР)
ЛЖ. Соответственно изменению размеров ЛЖ увеличивался его объем, преимущественно при наличии сочетанной патологии, что с учетом сохранения нормальных значений сердечного индекса свидетельствует об умеренно выраженной систолической дисфункции.

Таким образом, систолическая дисфункция (ФВ ЛЖ < $45 \%)$ была выявлена лишь у 147 (29,5\%) больных 1-й группы, 293 (40,6 \%) больных 2-й группы и 181 (34,9\%) пациента 3-й группы, при этом у больных с сочетанной патологией низкая ФВ ЛЖ встречалась статистически значимо чаще. Полученные результаты согласуются с данными исследования ЭПОХА-О-ХСН [7]. Необходимо отметить, что у больных 2-й группы со сниженной ФВ ЛЖ $(46,0 \%)$ $\mathrm{XCH,} \mathrm{по} \mathrm{ШОКС,} \mathrm{была} \mathrm{более} \mathrm{тяжелой} \mathrm{(7,3} \mathrm{балла).}$

При оценке изменений геометрии ЛЖ выявлено увеличение массы миокарда ЛЖ (ММЛЖ) и индекса ММЛЖ у 206 (41,4 \%) пациентов 1-й группы, 362 $(50,2 \%)-2$-й группы и $228(44,0 \%)-3$-й, при этом

Таблица 3

Показатели центральной и внутрисердечной гемодинамики по группам

\begin{tabular}{|c|c|c|c|}
\hline Показатели & 1-я группа (ХОБЛ), $n=498$ & 2-я группа (ХОБЛ и ИБС), $n=721$ & 3-я группа (ИБС), $n=518$ \\
\hline лП (мм) & $38,90 \pm 0,26$ & $43,10 \pm 0,27^{*}$ & $41,30 \pm 0,25^{* *}$ \\
\hline КСР лЖ (мм) & $35,10 \pm 0,18$ & $42,10 \pm 0,24^{*}$ & $37,80 \pm 0,28^{* *}$ \\
\hline КДР ЛЖ (мм) & $51,10 \pm 0,34$ & $55,20 \pm 0,26^{*}$ & $52,30 \pm 0,27^{* *}$ \\
\hline ксо ЛЖ, мл & $51,20 \pm 0,59$ & $79,00 \pm 0,49^{*}$ & $61,30 \pm 0,54^{* *}$ \\
\hline кдо лж, мл & $124,40 \pm 1,06$ & $148,70 \pm 0,95^{*}$ & $132,30 \pm 1,03^{\star *}$ \\
\hline ММлЖ, г & $286,00 \pm 2,81$ & $345,90 \pm 2,34^{*}$ & $304,70 \pm 2,30$ ** \\
\hline ИНMM, $\mathrm{r} / \mathrm{M}^{2}$ & $151,30 \pm 2,42$ & $162,40 \pm 1,82^{*}$ & $154,70 \pm 2,48^{* *}$ \\
\hline тзслЖ (мм) & $12,00 \pm 0,13$ & $12,40 \pm 0,07^{*}$ & $12,20 \pm 0,09^{* *}$ \\
\hline ТМЖП (мм) & $11,90 \pm 0,10$ & $12,50 \pm 0,10^{*}$ & $12,30 \pm 0,05^{\star *}$ \\
\hline уо лЖ, мл & $74,20 \pm 1,01$ & $67,30 \pm 0,74^{*}$ & $70,10 \pm 0,64^{* *}$ \\
\hline ФВ ЛЖ (\%) & $58,80 \pm 0,37$ & $46,00 \pm 0,35^{*}$ & $54,50 \pm 0,33^{* *}$ \\
\hline$\Delta \mathbf{S}, \%$ & $31,90 \pm 0,16$ & $23,40 \pm 0,21^{*}$ & $27,70 \pm 0,20^{* *}$ \\
\hline МО, л/мин & $5,90 \pm 0,06$ & $5,70 \pm 0,05^{*}$ & $5,50 \pm 0,06^{* *}$ \\
\hline УИ, мл/м $/ \mathrm{M}_{2}$ & $38,70 \pm 0,35$ & $31,20 \pm 0,24^{*}$ & $37,50 \pm 0,25^{* *}$ \\
\hline СИ, л/мин/м² & $3,00 \pm 0,07$ & $2,70 \pm 0,04^{*}$ & $2,80 \pm 0,05^{\star *}$ \\
\hline ПП (мм) & $38,10 \pm 0,63$ & $42,10 \pm 0,55^{*}$ & $37,10 \pm 0,59^{* *}$ \\
\hline КДР ПЖ (мм) & $24,90 \pm 0,21$ & $27,5 \pm 0,16^{*}$ & $21,7 \pm 0,30^{* *}$ \\
\hline ТПС пЖ (мм) & $5,10 \pm 0,11$ & $6,30 \pm 0,09^{*}$ & $4,00 \pm 0,09^{* *}$ \\
\hline ФВ ПЖ (\%) & $49,10 \pm 0,34$ & $47,10 \pm 0,21^{*}$ & $55,30 \pm 0,29^{* *}$ \\
\hline кСО ПЖ, мл & $72,20 \pm 0,73$ & $79,10 \pm 0,63^{*}$ & $61,50 \pm 0,87^{* *}$ \\
\hline кДО ПЖ, мл & $136,50 \pm 1,40$ & $144,60 \pm 1,21^{*}$ & $118,90 \pm 1,75^{* *}$ \\
\hline
\end{tabular}

Примечания: ЛП - левое предсердие; КДР - конечно-диастолический размер; КСР - конечно-систолический размер; КДО - конечно-диастолический объем; КСО - конечно-систолический объем; ММЛЖ - масса миокарда ЛЖ; ИММЛЖ - индекс ММЛЖ; ТЗСЛЖ - толщина задней стенки ЛЖ; ТМЖП - толщина межжелудочковой перегородки; Уо - ударный объем; $\Delta S$ - степень укорочения передне-заднего размера ЛЖ; МО - минутный объем; УИ - ударный индекс; СИ - сердечный индекс; ПП - правое предсердие; ПЗР пЖ - переднезадний размер ПЖ; ТПСПЖ - толщина передней стенки ПЖ. * - статистически значимые различия $(p<0,05)$ между 1-й и 2-й группами; ** - статистически значимые различия ( $p<$ 0,05) между 2-й и 3-й группами. 
Таблица 4

Параметры потока в выносящем тракте ПЖ по данным допплерэхокардиографии

\begin{tabular}{l|c|c|c}
\multicolumn{1}{r}{ Показатели } & 1-я группа (ХОБЛ), $n=184$ & 2-я группа (ХОБЛ и ИБС), $n=211$ & 3-я группа (ИБС), $n=167$ \\
Vp, м/с & $0,91 \pm 0,01$ & $0,95 \pm 0,01$ & $0,87 \pm 0,01$ \\
\hline AT, мС & $134,70 \pm 2,02$ & $125,60 \pm 1,77^{*}$ & $137,10 \pm 1,86^{* *}$ \\
ET, мС & $367,10 \pm 2,72$ & $379,40 \pm 2,23^{*}$ & $364,40 \pm 2,35^{* *}$ \\
AT / ЕT & $0,36 \pm 0,003$ & $0,33 \pm 0,005^{*}$ & $0,38 \pm 0,001^{* *}$
\end{tabular}

Примечания: Vp - максимальная скорость потока в выносящем тракте Пж; . * - статистически значимые различия $(p<0,05)$ между 1-й и 2-й группами; ** - статистически значимые различия $(p<0,05)$ между 2-й и 3-й группами.

ремоделирование ЛЖ эксцентрического, как известно, более неблагоприятного в прогностическом отношении, статистически значимо чаще выявлялось во 2-й группе (у 184 (25,5\%) больных).

Гипертрофия ПЖ (толщина передней стенки $>0,4$ см) и его дилатация (КДР ПЖ > 2,6 см) чаще обнаруживалась у пациентов 2-й группы. В связи с тем, что ценную информацию о состоянии ПЖ можно получить при изучении потока в выносящем тракте ПЖ, нами проведено исследование основных параметров данного потока с учетом условий допплеровского исследования (табл. 4).

У больных 2-й группы отмечалось снижение AT, увеличение ЕT, уменьшение отношения АT / ET по сравнению с 1-й и 3-й группами, что является характерным признаком легочной гипертензии. Можно отметить более выраженное уменьшение отношения AT / ET у пациентов с сочетанной патологией по сравнению с больными ХОБЛ.

СрДЛА было оценено у 184 (37,0 \%) больных 1-й группы, 211 (29,3 \%) больных 2-й группы и 167 (32,2 \%) пациентов 3-й группы. Наиболее значительное повышение СрДЛА отмечено в группах больных ХОБЛ $(24,7 \pm 0,41$ мм рт. ст.) и при наличии сочетанной патологии $(29,9 \pm 0,27$ мм рт. ст.), где средние значения СрДЛА были статистически значимо выше по отношению к 3-й группе $(21,7 \pm 0,07$ мм рт. ст.). Выявление нарушений диастолического наполнения сердца важно, т. к. расстройства диастолы более тесно, чем расстройства систолы, связаны с тяжестью клинического состояния пациентов, степенью снижения толерантности к нагрузкам и качеством жизни [11].

Нарушение диастолической функции (ДФ) ПЖ, обнаруженное у 154 (83,7 \%) больных, у большинства из них характеризовалось I типом ДД, что проявлялось незначительным снижением пика максимальной скорости раннего диастолического наполнения (Е), увеличением пика максимальной скорости предсердного диастолического наполнения (А), снижением $\mathrm{E} / \mathrm{A}<1$ с одновременным ростом времени изоволюмического расслабления ПЖ (IVRT пж) и времени замедления потока в фазу раннего наполнения ПЖ (DT пж). II тип ДД выявлен у 20 (10,9\%) пациентов (табл. 5). Нарушение диастолической функции ПЖ, видимо, обусловлено замедлением расслабления гипертрофированного миокарда ПЖ и увеличением постнагрузки.

Во 2-й группе ДД ПЖ выявлена у 194 (91,9 \%) больных. Необходимо отметить, что помимо I типа ДД у 133 (63,0 \%) пациентов и II типа ДД у 38 $(18,0 \%)$ больных, определялся III тип ДД - у 23 $(10,9 \%)$ человек. При этом скорость нарастания пика Е и отношение E / А значительно повысились ( $\mathrm{E} / \mathrm{A}->2,0)$, а скорость предсердного наполнения уменьшилась, что сопровождалось укорочением времени изоволюмического расслабления ЛЖ (IVRT и времени замедления потока в фазу раннего наполнения ЛЖ (DT

При анализе диастолической функции ПЖ у 95 (56,9 \%) больных 3-й группы показатели были нормальными, нарушения диастолической функции ПЖ по I типу выявлены у 72 (43,1 \%) пациентов. Следует отметить, что поражение ПЖ крайне редко возникает при интактном ЛЖ и наличие признаков диастолической дисфункции ПЖ при нормальных показателях диастолического наполнения ЛЖ у больных ХСН свидетельствует о псевдонормализации последних, что подтверждается результатами проведенного исследования.

Таблица 5 Показатели диастолической функции ПЖ и ЛЖ по группам

\begin{tabular}{|c|c|c|c|}
\hline Показатели & 1-я группа (ХОБЛ), $n=184$ & 2-я группа (ХОБЛ и ИБС), $n=211$ & 3-я группа (ИБС), $n=167$ \\
\hline$E_{п ж}, M / c$ & $0,43 \pm 0,01$ & $0,49 \pm 0,01^{*}$ & $0,45 \pm 0,01^{* *}$ \\
\hline 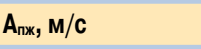 & $0,49 \pm 0,01$ & $0,51 \pm 0,01$ & $0,40 \pm 0,01^{* *}$ \\
\hline$E / A$ & $0,87 \pm 0,03$ & $0,96 \pm 0,03^{*}$ & $1,12 \pm 0,04^{* *}$ \\
\hline$D T_{n \mathfrak{H}}, \mathrm{M} / \mathrm{C}$ & $249,40 \pm 2,82$ & $227,40 \pm 3,35^{\star}$ & $191,70 \pm 3,10^{* *}$ \\
\hline IVRT $_{\text {пж, }}, \mathrm{M} / \mathrm{C}$ & $115,70 \pm 1,96$ & $106,70 \pm 1,35^{*}$ & $88,60 \pm 1,38^{* *}$ \\
\hline$E_{\text {пж, }}, \mathbf{M} / \mathrm{c}$ & $0,56 \pm 0,01$ & $0,74 \pm 0,01^{*}$ & $0,53 \pm 0,01^{* *}$ \\
\hline$A_{\text {лж, }}, \mathrm{m} / \mathrm{c}$ & $0,64 \pm 0,01$ & $0,52 \pm 0,01^{*}$ & $0,68 \pm 0,01^{* *}$ \\
\hline $\mathbf{E} / \mathbf{A}$ & $0,87 \pm 0,02$ & $1,45 \pm 0,01^{*}$ & $0,79 \pm 0,01^{* *}$ \\
\hline $\mathrm{DT}_{\text {пж, }}, \mathrm{M} / \mathrm{C}$ & $212,60 \pm 2,13$ & $175,60 \pm 2,43^{*}$ & $246,40 \pm 3,20^{* *}$ \\
\hline IVRT $_{\text {пк }}, \mathbf{M} / \mathbf{C}$ & $105,30 \pm 1,53$ & $87,80 \pm 0,99^{*}$ & $125,10 \pm 1,25^{* *}$ \\
\hline
\end{tabular}

Примечания: * - статистически значимые различия $(p<0,05)$ между 1-й и 2-й группами; ** - статистически значимые различия $(p<0,05)$ между 2-й и 3-й группами. 
У 45 (24,5 \%) больных 1-й группы нарушения диастолической функции в виде замедленной релаксации ЛЖ приводили к перераспределению диастолического наполнения в пользу предсердного компонента, что проявлялось снижением амплитуды пика Е, увеличением высоты пика А и уменьшением соотношения Е / A $<1$. Одновременно возрас-

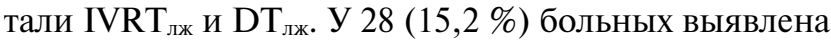
"псевдонормализация" диастолического наполнения ЛЖ с увеличением значений максимальной скорости раннего диастолического наполнения при одновременном уменьшении скорости кровотока во время систолы предсердий. Значения IVRT лж $_{\text {и }} \mathrm{DT}_{\text {лж }}$ у этих больных не отличались от нормальных параметров. Рестриктивный тип ДД ЛЖ определялся у 15 (8,2 \%) больных.

Обращает на себя внимание тот факт, что ДД ПЖ и ЛЖ у больных ХОБЛ нарастала асинхронно, только у 1/2 пациентов 1-й группы были нарушения диастолической функции как ЛЖ, так и ПЖ (т. е. можно говорить о диастолической дисфункции сердца в целом). У 34,2 \% больных встречалась изолированная ДД ПЖ, т. е. в этой группе больных признаки ДД сердца возникли в ПЖ при неизмененной диастолической функции (ДФ) ЛЖ. У 12,0 \% пациентов регистрировалось только нарушение ДФ ЛЖ, а выраженные нарушения кровенаполнения ПЖ отсутствовали.

При оценке ДД ЛЖ в группе больных с сочетанной патологией у 98 (46,5 \%) человек отмечалось нарушение ДФ ЛЖ по I типу, у 51 (24,2 \%) пациента - по II (псевдонормальному) типу, у 32 (15,2 \%) выявлялся 3-й вариант спектра трансмитрального кровотока, отличающийся значительным замедлением IVRT $_{\text {лж }}$ и $\mathrm{DT}_{\text {лж}}$, несмотря на нарастание скорости потока раннего наполнения и уменьшение фракции предсердного наполнения. Наличие 3-го варианта спектра трансмитрального кровотока характерно именно для больных с сочетанием ХОБЛ и ИБС и является, повидимому, результатом сложных диастолических нарушений и последующих гемодинамических компенсаторных изменений, действующих через повышение давления и в левых камерах сердца, и в системе легочной артерии. При анализе данных допплерэхокардиографии учитывалось, что с возрастом, по мере снижения эластичности миокарда, снижается скорость Е как ЛЖ, так и ПЖ и повышается IVRT 2-й группы при всех типах ДД ЛЖ, как правило, отмечались аналогичные изменения допплерографических индексов наполнения ПЖ.

У 22,8 \% пациентов с ИБС показатели ДФ Лж были нормальными, у 95 (56,9 \%) больных отмечались нарушения ДФ по І типу, у 23 (13,8 \%) человек по II типу и у 11 (6,6 \%) человек - по III типу.

\section{Заключение}

Таким образом, по результатам эхокардиодопплерографического исследования можно констатиро- вать, что во всех 3 группах происходили процессы ремоделирования ЛЖ и ПЖ. У пациентов с ХОБЛ отмечались признаки гипертрофии ПЖ и увеличение его размеров. Во 2-й группе больных при наличии сочетанной патологии необходимо отметить наиболее выраженное увеличение размеров и толщины стенок ЛЖ и ПЖ, увеличение ММЛЖ и снижение насосной функции ЛЖ. В 3-й группе у пациентов с ИБС наблюдались увеличение левых отделов сердца, повышение ММЛЖ, а также некоторое снижение показателей сократимости ЛЖ.

\section{Литература}

1. Chen J.C., Mannino M.D. Wordlwide epidemiology of chronic obstructive pulmonary disease. Curr. Op. Pulm. Med. 1999: 5: 93-99.

2. Айсанов З.Р., Калманова Е.Н., Чучалин А.Г. Хроническая обструктивная болезнь легких в сочетании с сердечнососудистыми заболеваниями: лечение ингаляционными холинолитическими препаратами. Тер. арх. 2004; 12: $81-82$.

3. Глобальная стратегия диагностики, лечения и профилактики хронической обструктивной болезни легких. Пересмотр 2003 г.: Пер. с англ. под ред. А.Г.Чучалин. М.: Атмосфера; 2003.

4. Батыралиев Т.А., Махмутходжаев С.А., Першуков И.В. $u \partial p$. Легочная гипертензия и правожелудочковая недостаточность. Часть I. Кардиология 2006; 2: 74-82.

5. Karatasakis G.T., Karagounis L.A., Kalyvas P.A. et al. Prognostic significance of echocardiographically estimated right ventricular shortening in advanced heart failure. Am. J. Cardiol. 1998; 82 (3): 329-334.

6. Kohama A., Tanouchi J., Masatsugu H. et al. Pathologic involvement of the left ventricle in chronic cor pulmonale. Chest 1990; 98: 794-800.

7. Национальные рекомендации ВНОК и ОССН по диагностике и лечению ХСН (второй пересмотр). Сердеч. недостат. 2006; 7 (2): 52-80.

8. Reybrouck T. Clinical usefulness and limitations of the 6-minute walk test in patients with cardiovascuiar or pulmonary disease. Chest 2003; 123 (2): 325-327.

9. Kitabatake A., Inoue M., Asao M. et al. Noninvasive evaluation of pulmonary hypertension by a pulsed doppler technique. Circulation 1983; 68: 302-309.

10. Ishikura F., Redfield M.M. Doppler echocardiography assessment of diastolic function in congestive heart failure: emphasis on clinical utility. Heart Fail. 1998; 14: 78-96.

11. Дембо А.Г. Недостаточность функции внешнего дыхания. Л: Медицина; 1957.

12. Канаев Н.Н. О формах и степенях недостаточности внешнего дыхания. В кн.: Руководство по клинической физиологии дыхания. М: Медицина; 1980: 346-358.

13. Диагностика и коррекция нарушений липидного обмена с целью профилактики и лечения атеросклероза. Российские рекомендации. Разработаны Комитетом экспертов ВНОК. Кардиоваск. тер. и профилакт. 2004; прил.: $1-36$.

Поступила 17.09.07 (c) Шойхет Я.Н., Клестер Е.Б., 2008 удк 616.24-036.12-06:616.12-008.46 